\title{
Gold Nanoparticles as Assisted Matrices for the Detection of Biomolecules in a High-Salt Solution through Laser Desorption/Ionization Mass Spectrometry
}

\author{
Hsin-Pin $\mathrm{Wu}^{\mathrm{a}}{ }^{\mathrm{C}}$ Cheng-Ju Yu, ${ }^{\mathrm{a}}$ Chin-Yu Lin, ${ }^{\mathrm{a}}$ Yen-Hsiu Lin, ${ }^{\mathrm{a}}$ \\ and Wei-Lung Tseng ${ }^{a, b}$ \\ ${ }^{a}$ Department of Chemistry, National Sun Yat-sen University, Taiwan \\ ${ }^{b}$ National Sun Yat-sen University-Kaohsiung Medical University Joint Research Center, Kaohsiung, Taiwan
}

\begin{abstract}
Citrate-capped gold nanoparticles (AuNPs) serve as matrices for the determination of biomolecules in a high-salt solution through matrix-assisted laser desorption/ionization time-of-flight mass spectrometry (MALDI-TOF-MS). In the case of using 2,5-dihydroxybenzoic acid (2,5-DHB) as a matrix, the signal intensities of neutral steroids were severely suppressed in a high-salt solution. A high concentration of $\mathrm{NaCl}$ caused the formation of the sodium adduct ions during the desorption/ionization process, resulting in a decrease of the signal intensities of the protonated ions. In comparison, by applying AuNP-assisted LDI-TOF-MS, the signal intensities of neutral steroids remained almost constant when the concentration of $\mathrm{NaCl}$ was increased to $500 \mathrm{mM}$. Because the use of citrate-capped AuNPs as matrices primarily offers alkali metal ion adducts, AuNP matrices have a higher tolerance to high $\mathrm{NaCl}$ concentrations relative to that of 2,5-DHB matrices. The relevant phenomena are also discovered in the case of analysis of neutral carbohydrate, monosialoganglioside, indolamine, and angiotensin I. The quantification of small molecules in a high-salt solution has been accomplished by AuNP-assisted LDI-TOF-MS coupled to a unique sample preparation, in which samples are deposited onto the sample plate before AuNPs. The present method has been further applied to the determination of urea, creatinine, uric acid, and glucose in a urine sample. (J Am Soc Mass Spectrom 2009, 20, 875-882) (c) 2009 American Society for Mass Spectrometry
\end{abstract}

S ince its invention in 1987, matrix-assisted laser desorption/ionization time-of-flight mass spectrometry (MALDI-TOF-MS) has became a powerful technique in biochemical analysis [1]. Although many groups have demonstrated that the use of an organic chemical matrix in MALDI-TOF-MS is capable of detecting peptides, proteins, and nucleic acids [2], there are still unresolved problems in the general application of MALDI-TOF-MS: (1) The cocrystallization of analytes with matrices does not produce homogeneous mixtures, which cause hot spots and thereby require sweet-spot searching [3]. (2) MALDI-TOF-MS is incapable of detecting small molecules because of the high background signals of small organic matrices, which are present in the low-mass region (<500 Da) [4]. (3) The presence of salts in a sample solution will increase the intensities of salt-adducted forms [5]. Thus, the desalting devices such as microextraction tips, polymeric membranes, and mini-C18 columns are helpful in MALDI-TOF-MS [6]. (4) The neutral molecules such as

Address reprint requests to Dr. Wei-Lung Tseng, National Sun Yat-sen University, Department of Chemistry, 70, Lien-hai Road, Kaohsiung, Taiwan 804. E-mail: tsengwl@mail.nsysu.edu.tw carbohydrates are poorly ionized by MALDI because of the absence of either a basic or an acidic group in their structures [7].

To overcome these problems, the use of inorganic material as a matrix has been introduced for the determination of analytes ranging from small organic molecules to biopolymers such as proteins and peptides [8-18]. Tanaka et al. [8] pioneered the research in this field and they reported the use of $30-\mathrm{nm}$ cobalt nanoparticles (NPs) (suspended in glycerol) as matrices for the analysis of lysozyme. It is suggested that cobalt NPs take the advantages of a large surface area, high photoabsorption, and low heat capacity compared with those of microparticles. Inspired by Tanaka's results, a series of inorganic micro- and nanomaterials-such as graphite particles [9], gold NPs (AuNPs) [10], silver NPs [11], titanium dioxide NPs [12], silicon NPs [13], Au nanorods [14], and carbon nanotubes [15] - have been studied as potential inorganic matrices. Moreover, matrix-free LDI-MS has been proposed using porous silicon as a sample target for the analysis of small molecules such as peptides, drugs, surfactants, and carbohydrates [16]. This well-known technique is called desorption/ionization on porous silicon (DIOS) [17]. In 
addition to DIOS, other approaches, including sol-gels, carbon-based microstructures, silicon nanowire-based silicon wafers, or germanium nanodot-based chips [16, 18], have been used in matrix-free LDI-MS.

Compared with organic chemical matrices, nanomaterial matrices offer the advantages of eliminating matrix ion interference and improving the sample homogeneity [8-18]. Moreover, nanomaterials have also been widely used as affinity probes to simultaneously enrich and isolate the target species. Flocculated and trapped mixtures can be detected using nanomaterials or organic molecules as matrices $[12,19,20]$. Recently, the determination of neutral carbohydrates has been accomplished by AuNP-assisted LDI [21]. With this approach, the ionization efficiency of neutral carbohydrates can be greatly amplified without derivatization steps. We also found that a unique sample preparation, in which samples are deposited onto the sample plate before bare AuNPs, can provide better detection sensitivity and sample homogeneity when compared with (1) a deposition of a mixture of matrix and sample onto the sample plate and (2) a deposition of bare AuNPs onto the sample plate before the sample [22].

Herein, we evaluated the feasibility of using citratecapped AuNPs as MALDI matrices for the determination of progesterone, testosterone, and cortisol in a high-salt solution. We carefully investigated the effect of $\mathrm{NaCl}$ concentration on shot-to-shot reproducibility and detection sensitivity when 2,5-dihydroxybenzoic acid (2,5-DHB) or AuNPs served as matrices. This practical method was further validated by the analysis of carbohydrate, monosialoganglioside (GM1), indolamine, and angiotensin I in a high-salt solution. It should be mentioned that neutral steroids and carbohydrates, which are notoriously difficult to be ionized using organic chemical matrices $[7,23]$, are cationized very efficiently by AuNP-assisted LDI-TOF-MS, even if they have been present in a high-salt solution.

\section{Experimental}

\section{Chemicals}

Progesterone, testosterone, cortisol, ribose, glucose, maltose, 5-hydroxyindole acetic acid (5-HIAA), tryptophan, GM1 (bovine brain), bradykinin, angiotensin II, angiotensin $\mathrm{I}$, and substance $\mathrm{P}$ were purchased from Sigma Chemical (St. Louis, MO, USA). Hydrogen tetrachloroaurate (III) dehydrate, 2,5-DHB, trisodium citrate, sodium chloride, methanol, acetonitrile, and sodium borohydride were obtained from Aldrich (Milwaukee, WI, USA). Trifluoroacetic acid (TFA) was purchased from Merck (Darmstadt, Germany). Milli-Q ultrapure water was used in all of the experiments. Stock solutions of steroids and GM1 (10 mM) were prepared in methanol.

\section{Apparatus}

A double-beam UV-visible spectrophotometer (Cintra 10e, GBC Scientific Equipment Pty Ltd., Dandenong, Victoria, Australia) and an H7100 transmission electron microscope (TEM; Hitachi High-Technologies Corp., Tokyo, Japan) operating at $75 \mathrm{keV}$ were used to examine the absorbance and particle size of the AuNPs, respectively. MS experiments were performed in the positive-ion mode on a reflectron-type time-of-flight (TOF) mass spectrometer (AutoFlex, Bruker Daltonics, Billerica, MA, USA), which was equipped with a 3-m flight tube and a 337-nm nitrogen laser. The available accelerating voltages existed in the range from +20 to $-20 \mathrm{kV}$. Each mass spectrum was generated by averaging 50 and 120 laser pulses. Multiple mass determinations $(n=10)$ were made on each sample $(200 \mu \mathrm{M})$ to provide a mean and relative standard deviation (RSD) for each mass of interest. Internal calibration across the mass range was performed and used the $[\mathrm{Au}]^{+}(\mathrm{m} / \mathrm{z}$ 196.9665), $\left[\mathrm{Au}_{2}\right]^{+}(\mathrm{m} / \mathrm{z} \text { 393.9330), [bradykinin }+\mathrm{H}]^{+}$ $(\mathrm{m} / \mathrm{z} \text { 757.3991), [angiotensin II }+\mathrm{H}]^{+}(\mathrm{m} / z$ 1046.5418), [angiotensin $\mathrm{I}+\mathrm{H}]^{+}(\mathrm{m} / z$ 1296.6848), and [substance $\mathrm{P}+\mathrm{H}^{+}(m / z$ 1347.7354).

\section{Synthesis of AuNPs}

On the basis of previous reports [24], a solution of the AuNPs was prepared by the chemical reduction of metal salt precursor (hydrogen tetrachloroaurate, $\left.\mathrm{HAuCl}_{4}\right)$ in a liquid solution. A solution of $\mathrm{HAuCl}_{4}$ $(0.35 \mathrm{mM}, 50 \mathrm{~mL})$ was heated to a boil before adding $34.0 \mathrm{mM}$ trisodium citrate $(0.8 \mathrm{~mL})$. The resulting solution was boiled for another $8 \mathrm{~min}$, during which time the color changed to deep red. The solution was cooled to room temperature with continuous stirring. The average size of the AuNPs estimated by TEM images was $13.2 \mathrm{~nm}$ with a standard deviation of $1.2 \mathrm{~nm}$. The maximum absorption wavelength of the AuNPs measured by UV-visible spectrophotometer was $520 \mathrm{~nm}$. The particle concentration of the AuNP solution determined by Beer's law was $13.0 \mathrm{nM}$; the extinction coefficient of $13.2 \mathrm{~nm}$ AuNPs at $520 \mathrm{~nm}$ was is approximately $10^{8} \mathrm{M}^{-1} \mathrm{~cm}^{-1}$ [25].

\section{Preparation of Samples}

Samples were prepared in a solution of $0-500 \mathrm{mM}$ $\mathrm{NaCl}$. A sample solution $(1 \mu \mathrm{L})$ was deposited first onto the sample plate (a stainless steel 384-well target, Bruker Daltonics) and allowed to dry in air. Subsequently, an equal volume of $13 \mathrm{nM}$ AuNPs or 20 $\mathrm{mg} / \mathrm{mL} 2,5-\mathrm{DHB}$ was deposited onto the first layer and allowed to dry in air at room temperature before MALDI-TOF-MS measurements. Previous studies demonstrated that this sample preparation coupled to AuNP-assisted LDI-TOF-MS is capable of providing better shot-to-shot reproducibility and detection sensi- 
tivity [22]. Note that 2,5-DHB was dissolved in acetonitrile $/ \mathrm{H}_{2} \mathrm{O}(70 / 30$, vol/vol) in $0.1 \%$ TFA.

\section{Analysis of Urine Samples}

Urine samples were collected from a healthy female. Without sample pretreatment, urine samples were directly deposited onto the sample plate and allowed to dry in air. Then, an equal volume of $13 \mathrm{nM}$ AuNPs or $20 \mathrm{mg} / \mathrm{mL}$ 2,5-DHB was deposited onto the first layer and allowed to dry in air before MALDITOF-MS measurements.

\section{Results and Discussion}

Effect of Salt Concentration

Figure 1 shows the mass spectra of three neutral steroids in the presence of $0-500 \mathrm{mM} \mathrm{NaCl}$ while $2,5-\mathrm{DHB}$ or AuNPs were used as matrices. In the sample prepa-
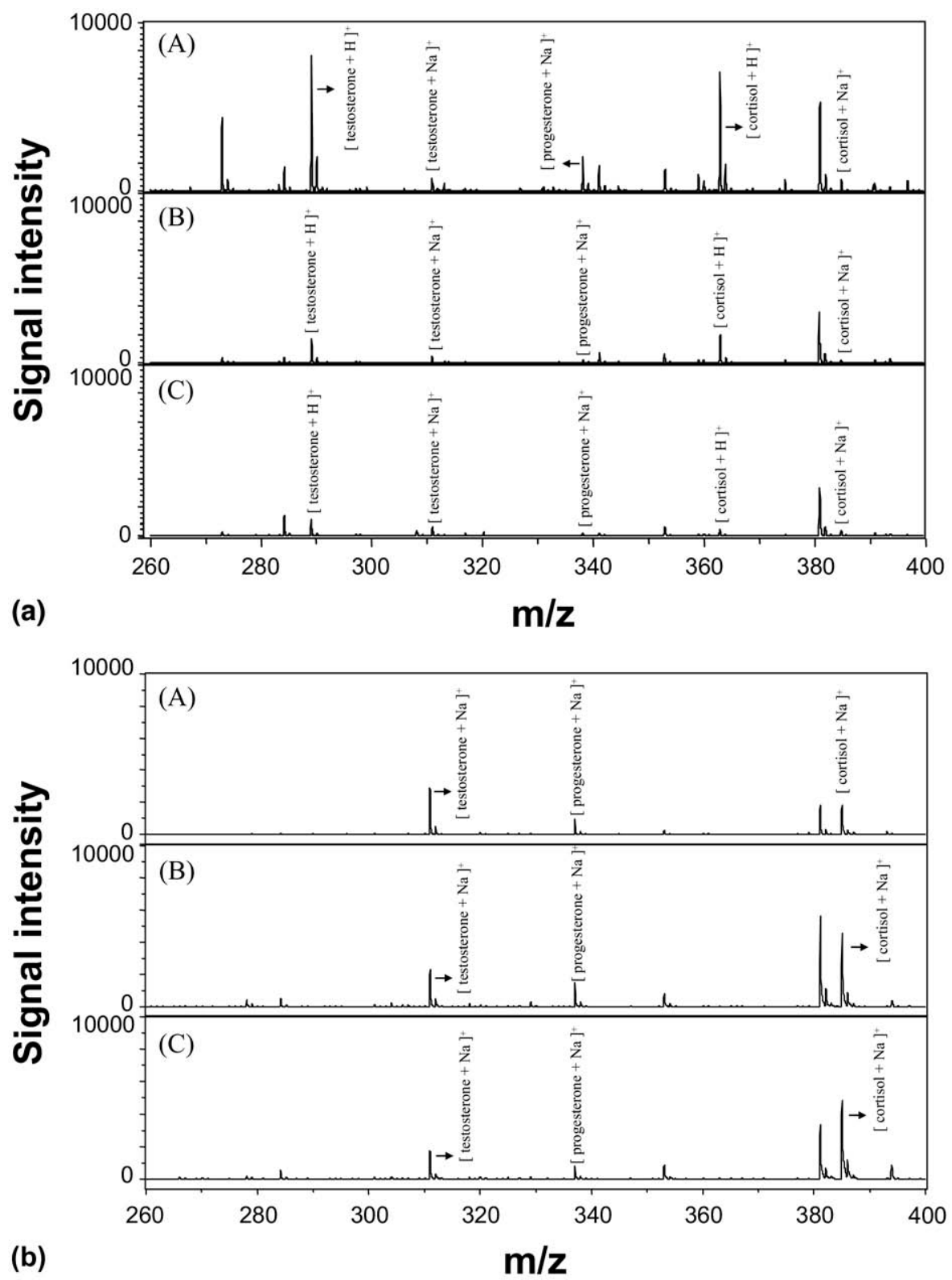

Figure 1. Effect of salt concentrations on the mass spectra of neutral steroids $(200 \mu \mathrm{M})$ when they are deposited first on the sample target and then (a) $20.0 \mathrm{mg} / \mathrm{mL} 2,5-\mathrm{DHB}$ and (b) $13.0 \mathrm{nM}$ AuNPs were deposited to the top of the sample layer. The samples were dissolved in (A) 0, (B) 100, and (C) $500 \mathrm{mM}$ $\mathrm{NaCl}$. (a) The peaks at $\mathrm{m} / \mathrm{z} 288.39,314.51$, and 362.46 are assigned to the [testosterone $+\mathrm{H}{ }^{+}$, [progesterone $+\mathrm{H}]^{+}$, and [cortisol $+\mathrm{H}^{+}$. (b) The peaks at $\mathrm{m} / z$ 311.37, 337.49, and 385.44 are assigned to the [testosterone $+\mathrm{Na}^{+}$, [progesterone $\left.+\mathrm{Na}\right]^{+}$, and $[\text {cortisol }+\mathrm{Na}]^{+}$. A total of 120 pulsed laser shots were applied under a laser fluence of $60 \mu \mathrm{J}$. 
ration, the analytes were deposited first onto the sample target and then 2,5-DHB or AuNPs were deposited onto the top of the sample layer. Expectedly, in the case of 2,5-DHB, the signal intensities of protonated steroids gradually decreased with increasing concentration of $\mathrm{NaCl}$ (Figure 1a). This is primarily attributed to the high concentration of $\mathrm{NaCl}$, which interferes with matrix crystal formation, resulting in signal suppression [26]. Another reason is that the presence of $\mathrm{NaCl}$ in a sample solution can cause the formation of the sodium adduct ions during the desorption/ionization process, leading to the low production of protonated ions [27]. Figure $1 b$ reveals the mass spectra of three neutral steroids after we used $13.0 \mathrm{nM}$ AuNPs to displace 2,5-DHB under identical conditions. The peaks detected at $m / z$ 311.04, 337.16, and 385.11 corresponded to [testosterone + $\mathrm{Na}]^{+}$, [progesterone $\left.+\mathrm{Na}\right]^{+}$, and $[\text {cortisol }+\mathrm{Na}]^{+}$, respectively. Compared with 2,5-DHB, the signal intensities of three neutral steroids obtained by AuNPassisted LDI remained almost constant with varying $\mathrm{NaCl}$ concentrations from 0 to $500 \mathrm{mM}$; this is primarily attributed to the fact that the analyte determined by AuNP-assisted LDI analysis has a great tendency to form sodium ion adducts [10, 19, 21, 22]. Moreover, the formation of multiple peaks from a single compound was not observed in AuNP-assisted LDI. Thus, no $\mathrm{MH}^{+}$ signal was obtained by AuNP-assisted LDI-TOF-MS. However, above $500 \mathrm{mM} \mathrm{NaCl}$, the signal intensities were suppressed, indicating that the maximum salt tolerance for AuNPs is $500 \mathrm{mM}$. These results provided clear evidence that AuNP matrices have a higher tolerance to high $\mathrm{NaCl}$ concentrations compared with that of 2,5-DHB matrices.

To understand whether the presence of salt affects the reproducibility of the signal intensity, a solution of cortisol containing $100 \mathrm{mM} \mathrm{NaCl}$ was detected by MALDI-TOF-MS when AuNPs or 2,5-DHB served as matrices (Figure 2). Variable signal intensities of cortisol were collected from 60 different sample spots. Compared with the use of $2,5-\mathrm{DHB}$, a decrease in the variability of the signal intensities of cortisol was observed using AuNP matrices. The RSDs of the signal intensity for AuNPs and 2,5-DHB were 21.40\% and $148.70 \%$, respectively. In the case of $2,5-\mathrm{DHB}$, the relatively poor reproducibility of the signal intensity was ascribed to the inhomogeneous cocrystallization of the analytes with the 2,5-DHB matrix. According to these results, we suggest that the use of AuNPs, compared with the use of 2,5-DHB, still provided better shot-toshot reproducibility in a high-salt solution.

\section{Carbohydrates, GM1, Indolamines, and Angiotensin I}

Encouraged by the successful analysis of neutral steroids in a high-salt solution, we further explored the other biomolecules by means of AuNP-assisted LDI-

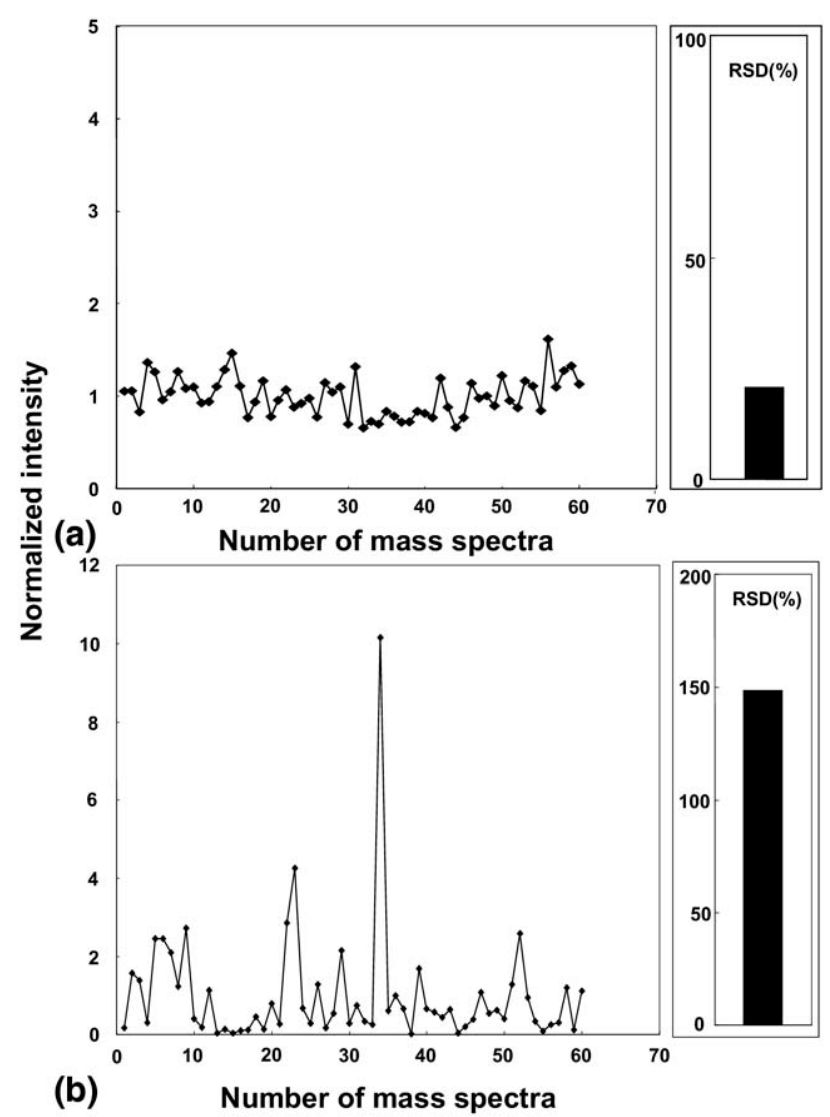

Figure 2. Plot of normalized (a) $[\text { cortisol }+\mathrm{Na}]^{+}$and (b) [cortisol $+\mathrm{H}^{+}$ion intensities of cortisol obtained from 60 different spots. A solution containing $100 \mu \mathrm{M}$ cortisol and 100 $\mathrm{mM} \mathrm{NaCl}$ was deposited first on the sample target and then (a) $13.0 \mathrm{nM}$ AuNPs and (b) $20.0 \mathrm{mg} / \mathrm{mL}$ 2,5-DHB were deposited to the top of the sample layer. The RSD of the data are presented as bar graphs. A total of 50 pulsed laser shots were applied under a laser fluence of $60 \mu \mathrm{J}$.

TOF-MS. Figure $3 a$ shows the mass spectrum of a mixture of ribose, glucose, and maltose in the presence of $500 \mathrm{mM} \mathrm{NaCl}$. When $13.0 \mathrm{nM}$ AuNPs were used as matrices, all carbohydrates produced $\mathrm{MNa}^{+}$species as the major ions. We assigned the peaks at $m / z 173.00$, 202.99, and 365.12 to [ribose $+\mathrm{Na}]^{+}$, [glucose $+\mathrm{Na}^{+}$, and [maltose $+\mathrm{Na}^{+}$, respectively. It should be mentioned that there was no peak corresponding to the molecular ions of three neutral carbohydrates when 2,5-DHB served as the matrix. Meanwhile, although GM1, composed of neutral glycosphingolipids and sialic acids, was detected under identical conditions (Figure 3b), two apparent peaks at $m / z 1279.16$ and 1307.87 were clearly present in the mass spectra derived from asialo GM1 (GM1 - Neu5Ac) with d18:1 sphinogosine and C18:0 fatty acid (d18:1-C18:0 or d18:1-C20: 0 ). Nakamura et al. [28] reported similar results for the determination of asialo GM1 while 2,5-DHB was dissolved in acetonitrile/water (1:1, vol/vol). Because AuNPs have a small heating capacity, the heat diffusion from AuNPs to analyte is fast during the laser pulse 


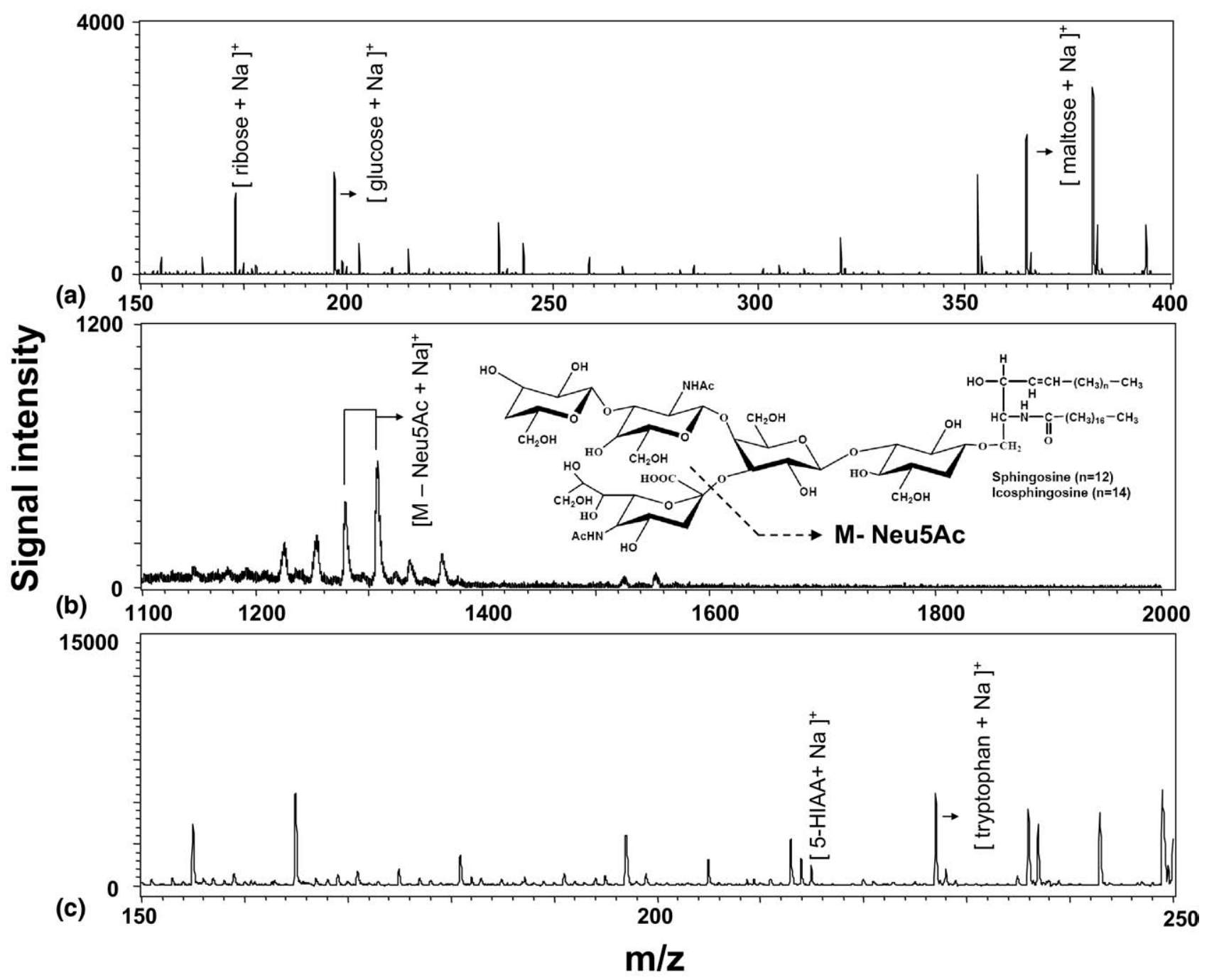

Figure 3. Mass spectra of (a) $200 \mu \mathrm{M}$ carbohydrates, (b) $10 \mu \mathrm{M}$ GM1, and (c) $200 \mu \mathrm{M}$ indolamines were obtained by AuNP-assisted LDI-TOF-MS. The samples were prepared in $500 \mathrm{mM} \mathrm{NaCl}$. A solution of $13.0 \mathrm{nM}$ AuNPs was used as matrices. (a) The peaks at $m / z$ 173.00, 202.99, and 365.12 are assigned to the [ribose $+\mathrm{Na}^{+}$, [glucose $+\mathrm{Na}{ }^{+}$, and [maltose $\left.+\mathrm{Na}\right]^{+}$. (b) The peaks at $\mathrm{m} / z 1279.16$ and 1367.87 are assigned to the [GM1 $-\mathrm{Neu} 5 \mathrm{Ac}+\mathrm{Na}]^{+}$. The other conditions are the same as those in Figure 1. (c) The peaks at $m / z 214.03$ and 227.04 are assigned to the $\left[5-\mathrm{HIAA}+\mathrm{Na}^{+}\right.$and [tryptophan $+\mathrm{Na}]^{+}$. The other conditions are the same as those in Figure 1.

[14]. Thus, the metastable heating of GM1 results in fragmentation (GM1 - Neu5Ac). This proposed method was also tested to detect indolamines in the presence of $500 \mathrm{mM} \mathrm{NaCl}$. The ionization of indolamines was successfully achieved by AuNP-assisted LDI-TOF-MS (Figure 3c). On the contrary, no peak corresponding to the molecular ions of indolamines was discovered when using 2,5-DHB matrices. It is of interest to investigate the effect of salt on the detection of peptide. Figure 4 a shows that the mass spectrum of angiotensin I containing $100 \mathrm{mM} \mathrm{NaCl}$ was obtained using 2,5-DHB matrices; we found the presence of a series of sodium adductions of angiotensin I. The inset is the mass spectrum of 2,5-DHB containing $100 \mathrm{mM}$ $\mathrm{NaCl}$ without the addition of angiotensin I. According to the result, it is suggested that serial peaks appearing at $m / z>1500$ were derived from the background of 2,5-DHB containing $\mathrm{NaCl}$ [29]. Figure 4 b shows that the mass spectrum of angiotensin I containing $100 \mathrm{mM}$ $\mathrm{NaCl}$ was obtained using AuNP matrices. The signal intensities of angiotensin I were relatively low in AuNP-assisted LDI-TOF-MS compared with the use of 2,5-DHB as matrices in MALDI-TOF-MS. However, the peaks observed in Figure $4 \mathrm{a}$ at $\mathrm{m} / \mathrm{z}>1500$ were absent in Figure 4b. As indicated in Figure 4c, even if $500 \mathrm{mM} \mathrm{NaCl}$ was added to the sample solution, the peak profile at $m / z>1500$ resembled that shown in Figure $4 \mathrm{~b}$. On the basis of these results, we point out that AuNP inorganic matrices can tolerate a sample solution containing a high concentration of $\mathrm{NaCl}$. Although DIOS [17] and silicon-NP-assisted LDI [13] also have higher salt tolerance, the preparation of 


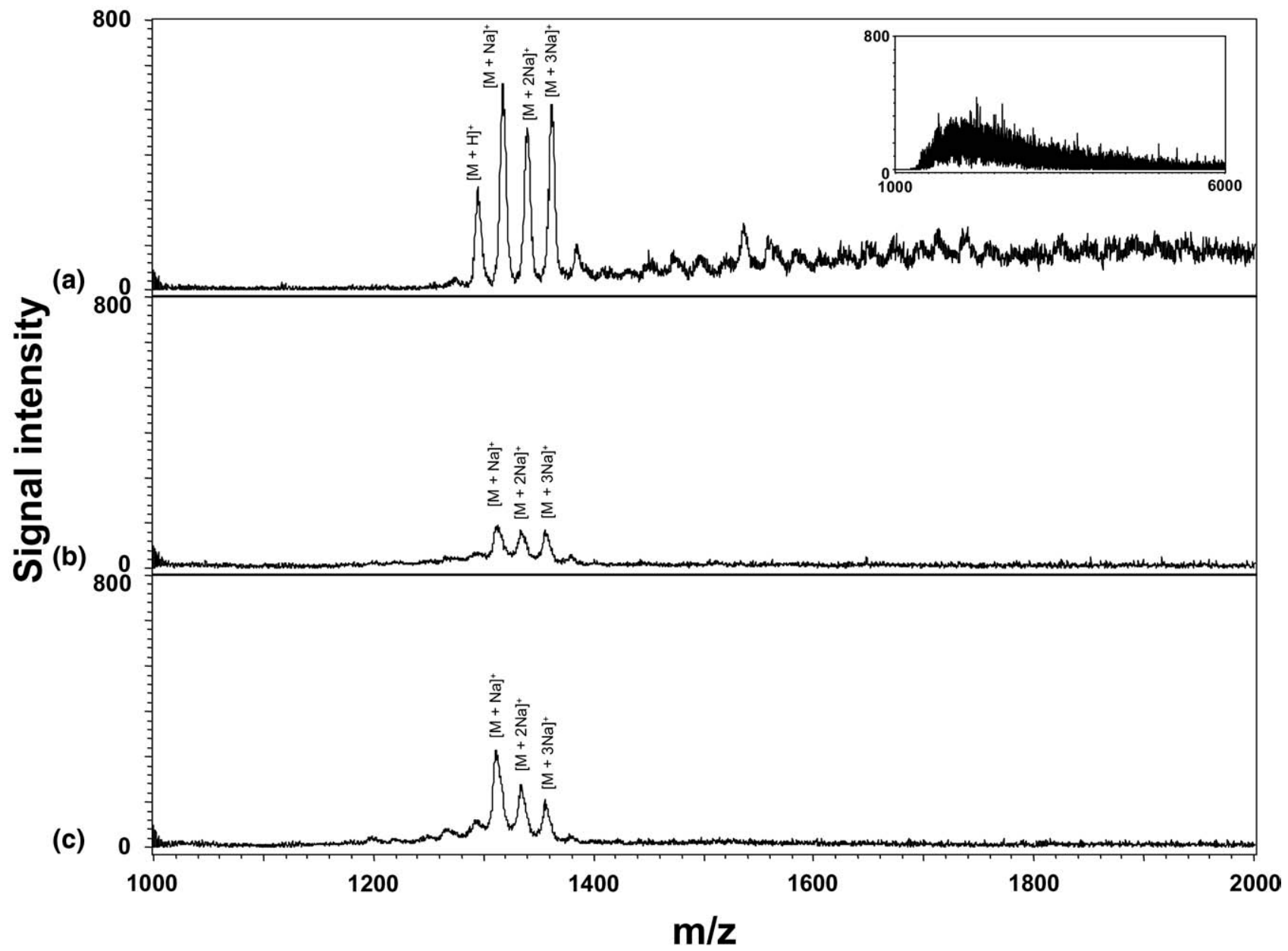

Figure 4. Mass spectra of angiotensin I $(100 \mu \mathrm{M})$ were obtained using (a) $20.0 \mathrm{mg} / \mathrm{mL} 2,5-\mathrm{DHB}$ and (b, c) $13.0 \mathrm{nM}$ AuNP matrices. The samples containing were prepared in (a, b) 100 and (c) $500 \mathrm{mM}$ $\mathrm{NaCl}$. Inset: Mass spectrum of 2,5-DHB containing $100 \mathrm{mM} \mathrm{NaCl}$. The other conditions are the same as those in Figure 1.

AuNPs is facile and does not require the use of UV light, electrochemical etching, HF etching, or fluorinated derivatives. Additionally, the detection of carbohydrates by DIOS is successful only in the presence of perfluorinated surfactants, which were spotted on the DIOS chip [30].

\section{Sensitivity and Application}

By applying AuNP-assisted LDI-TOF-MS, calibration curves were constructed by plotting the concentrations of analyte against measured signal intensities in the presence of $100 \mathrm{mM} \mathrm{NaCl}$. Table 1 shows that the

Table 1. Linear range, linearity, LOD and reproducibility for three steroids, three carbohydrates, two indolamines, GM1, and angiotensin I

\begin{tabular}{|c|c|c|c|c|c|}
\hline Analyte & Linear range $(\mu \mathrm{M})$ & $R^{2}$ & LOD (nM) & $m / z\left(\mathrm{Na}^{+} \text {adduct }\right)^{a}$ & $\operatorname{RSD}(\%)^{\mathrm{b}}$ \\
\hline Testosterone & 5 to 1000 & 0.9979 & 188.0 & 311.37 & 0.68 \\
\hline Progesterone & 5 to 1000 & 0.9992 & 398.9 & 337.49 & 2.22 \\
\hline Cortisol & 5 to 1000 & 0.9924 & 641.0 & 385.44 & 1.51 \\
\hline Ribose & 10 to 1000 & 0.9945 & 1395.0 & 173.00 & 1.40 \\
\hline Glucose & 10 to 1000 & 0.9992 & 393.4 & 202.99 & 0.90 \\
\hline Maltose & 10 to 1000 & 0.9912 & 785.3 & 365.12 & 0.03 \\
\hline 5-HIAA & 5 to 1000 & 0.9986 & 46.5 & 214.03 & 3.48 \\
\hline Tryptophan & 5 to 1000 & 0.9909 & 141.5 & 227.04 & 0.67 \\
\hline GM1 & 5 to 500 & 0.9878 & 1648.4 & 1307.48 & 0.04 \\
\hline Angiotensin I & 50 to 500 & 0.9910 & 5115.7 & 1320.80 & 0.04 \\
\hline
\end{tabular}

${ }^{\text {a Average }} \mathrm{m} / \mathrm{z}$ value $(n=10)$.

bThe mass accuracy of each compound $(200 \mu \mathrm{M})$ was obtained from 10 different spots. 
calibration curves for each analyte exhibited good linearity. The limits of detection (LODs) at a signal-tonoise $(\mathrm{S} / \mathrm{N})$ ratio of 3 were 188.0, 398.9, 641.0, 1395.0, 393.4, 785.3, 46.5, 141.5, 1648.4, and 5115.7 nM for testosterone, progesterone, cortisol, ribose, glucose, maltose, 5-HIAA, tryptophan, GM1, and angiotensin I, respectively. However, the sensitivity for three neutral steroids was insufficient to detect biological fluid in clinical samples [31]. We believe that the detection of neutral steroid in biological fluid can be successfully achieved through an extraction procedure coupled with AuNP-assisted LDI-TOF-MS [32].

We applied this proposed method to the analyses of a untreated urine sample. A normal urine sample contains about $130 \mathrm{mM} \mathrm{NaCl}$ [33]. Figure 5a shows that no peak was detected using 2,5-DHB matrices. Figure $5 \mathrm{~b}$ and $\mathrm{c}$ display the mass spectrum of urine samples through AuNP-assisted LDI-TOF-MS. The peaks at $m / z$ 83.03 and 98.98 are $\mathrm{Na}^{+}$and $\mathrm{K}^{+}$adducts of urea, which are the most abundant organic compounds in urine

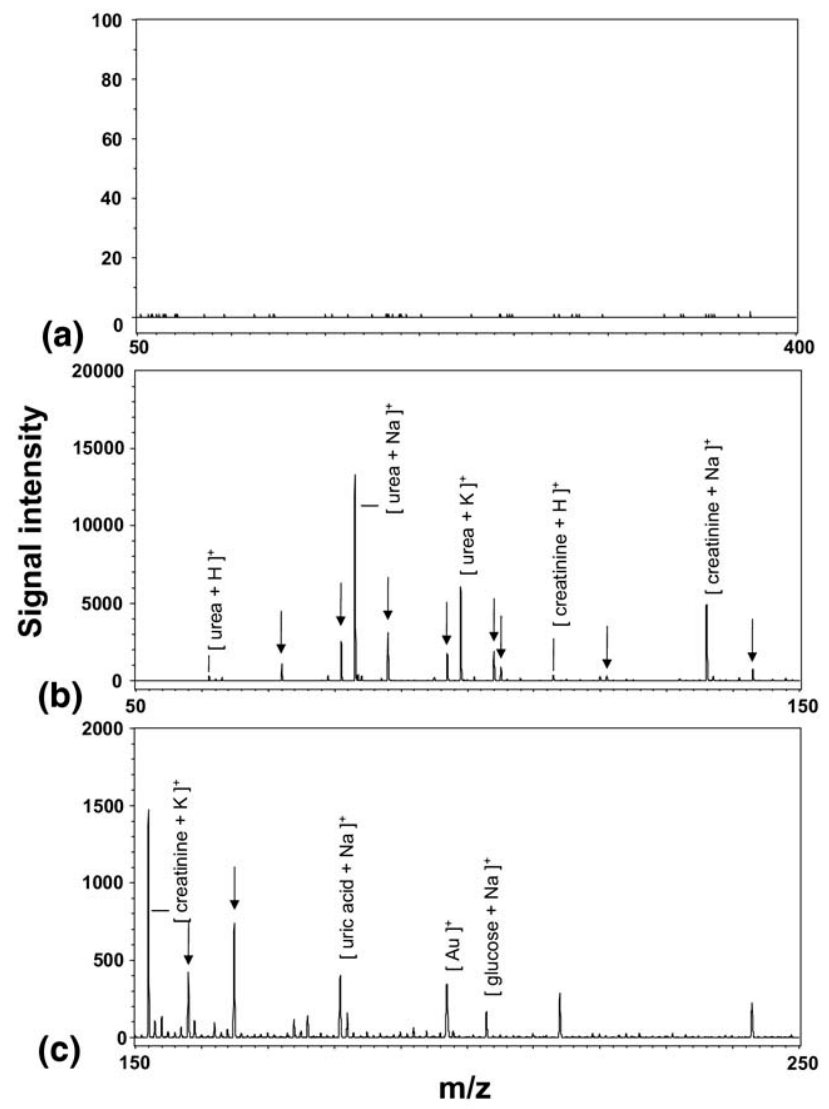

Figure 5. Mass spectrum of a urine sample was obtained using (a) $20.0 \mathrm{mg} / \mathrm{mL} 2,5-\mathrm{DHB}$ and (b, c) $13.0 \mathrm{nM}$ AuNP matrices. Note that the spectrum of a urine sample is divided into (b) and (c) because of the larger difference in scale. Peak identification: (b) $m / z$ 61.09, [urea $+\mathrm{H}]^{+} ; m / z$ 83.03, [urea $\left.+\mathrm{Na}\right]^{+} ; m / z$ 98.98, $[\text { urea }+\mathrm{K}]^{+} ; m / z$ 112.93, [creatinine $\left.+\mathrm{H}\right]^{+} ; m / z$ 136.09, [creatinine $+\mathrm{Na}]^{+}$. (c) $m / z$ 151.95, [creatinine $\left.+\mathrm{K}\right]^{+} ; m / z \neq 180.87$, $\left[\right.$ uric acid $+\mathrm{Na}^{+} ; m / z$ 196.97, $[\mathrm{Au}]^{+} ; m / z$ 202.91, [glucose + $\mathrm{Na}]^{+}$. The unidentified peaks were marked by arrow bars. The other conditions are the same as those in Figure 1.
[33]. Human urine also contains an abundance of urea, creatinine, uric acid, and glucose [33]. Figure 5b and c also display their corresponding mass spectra. The unidentified peaks, which were marked by arrows, most likely corresponded to amino acids, organic acids, and amines. Although the previous study also shows that two drugs, morphine and propafenone, in a urine sample can be detected by silicon-NP-LDI-TOF-MS [13], the peaks corresponding to creatinine, uric acid, and glucose are neither identified nor observed, probably attributable to the fact that silicon NPs should be washed with 2-propanol/ $\mathrm{H}_{2} \mathrm{O}$ (vol/vol, 50:50) before the analysis of silicon-NP-LDI-TOF-MS and the analytes were also prepared in 2-propanol $/ \mathrm{H}_{2} \mathrm{O}$ (vol/vol, 50:50).

\section{Conclusions}

We have demonstrated that AuNP inorganic matrices possess high-salt tolerance for the analysis of biomolecules by MALDI-TOF-MS while they are deposited first on the sample target, after which AuNPs are deposited onto the top of the sample layer. Compared to 2,5-DHB matrices, AuNPs offer a number of distinctive advantages. First, analytes can be directly detected and quantified in a high-salt solution by AuNP-assisted LDI-TOF-MS. Thus, this proposed method can be extended to the analysis of biological samples without a desalting step. Second, no serial peak was derived from the background of AuNPs containing $\mathrm{NaCl}$. Last, the use of AuNPs still provides better shot-to-shot reproducibility while samples are prepared in a high-salt solution. On the basis of these advantages, we believe that AuNP matrices have a potential advantage in analyzing biological samples containing a high-salt concentration.

\section{Acknowledgments}

We thank the National Science Council (NSC 97-2113-M-110-001) and National Sun Yat-sen University-Kaohsiung Medical University Joint Research Center for the financial support of this study.

\section{References}

1. Karas, M.; Bachman, D.; Bahr, U.; Hillenkamp, F. Matrix-Assisted Ultraviolet Laser Desorption of Non-Volatile Compounds. Int. J. Mass Spectrom. Ion Process. 1987, 78, 53-68.

2. Pan, C.; Xu, S.; Zhou, H.; Fu, Y.; Ye, M.; Zou, H. Recent Developments in Methods and Technology for Analysis of Biological Samples by MALDI-TOF-MS. Anal. Bioanal. Chem. 2007, 387, 193-204.

3. Tholey, A.; Heinzle, E. Ionic (Liquid) Matrices for Matrix-Assisted Laser Desorption/Ionization Mass Spectrometry: Applications and Perspectives. Anal. Bioanal. Chem. 2006, 386, 24-37.

4. Guo, Z.; Zhang, Q.; Zou, H.; Guo, B.; Ni, J. A Method for the Analysis of Low-Mass Molecules by MALDI-TOF Mass Spectrometry. Anal. Chem. 2002, 74, 1637-1641.

5. Bornsen, K. O. Influence of Salts, Buffers, Detergents, Solvents, and Matrices on MALDI-MS Protein Analysis in Complex Mixtures. Methods Mol. Biol. 2000, 146, 387-404.

6. Xu, Y. D.; Bruening, M. L.; Watson, J. T. Non-specific, On-Probe Cleanup Methods for MALDI-MS Samples. Mass Spectrom. Rev. 2003, 22, 429-440.

7. Harvey, D. J. Matrix-Assisted Laser Desorption/Ionization Mass Spectrometry of Carbohydrates. Mass Spectrom. Rev. 1999, 18, 349-451.

8. Tanaka, K.; Waki, H.; Ido, Y.; Akita, S.; Yoshida, Y.; Yoshida, T. Protein and Polymer Analyses Up to m/z 100000 by Laser Ionization Time-of- 
Flight Mass Spectrometry. Rapid Commun. Mass Spectrom. 1988, 2, 151-153.

9. Zhang, H.; Cha, S.; Yeung, E. S. Colloidal Graphite-Assisted Laser Desorption/Ionization MS and $\mathrm{MS}^{n}$ of Small Molecules. 2. Direct Profiling and MS Imaging of Small Metabolites from Fruits. Anal. Chem. 2007, 79, 6575-6584.

10. McLean, J. A.; Stumpo, K. A.; Russell, D. H. Size-Selected (2-10 nm) Gold Nanoparticles for Matrix Assisted Laser Desorption Ionization of Peptides. J. Am. Chem. Soc. 2005, 127, 5304-5305.

11. Chiu, T.-C.; Chang, L.-C.; Chiang, C.-K.; Chang, H.-T. Determining Estrogens Using Surface-Assisted Laser Desorption/Ionization Mass Spectrometry with Silver Nanoparticles as the Matrix. J. Am. Soc. Mass Spectrom. 2008, 19, 1343-1346.

12. Chen, C.-T.; Chen, Y.-C. $\mathrm{Fe}_{3} \mathrm{O}_{4} / \mathrm{TiO}_{2}$ Core/Shell Nanoparticles as Affinity Probes for the Analysis of Phosphopeptides Using $\mathrm{TiO}_{2}$ Surface-Assisted Laser Desorption/Ionization Mass Spectrometry. Anal. Chem. 2005, 77, 5912-5919.

13. Wen, X.; Dagan, S.; Wysocki, V. H. Small-Molecule Analysis with Silicon-Nanoparticle-Assisted Laser Desorption/Ionization Mass Spectrometry. Anal. Chem. 2007, 79, 434-444.

14. Chen, L.-C.; Yonehama, J.; Ueda, T.; Hori, H.; Hiraoka, K. Visible-Laser Desorption/Ionization on Gold Nanostructures. J. Mass Spectrom. 2007, $42,346-353$

15. Najam-ul-Haq, M.; Rainer, M.; Szabó, Z.; Vallant, R.; Huck, C. W.; Bonn, G. K. Role of Carbon Nano-Materials in the Analysis of Biological Materials by Laser Desorption/Ionization-Mass Spectrometry. J. Biochem. Biophys. Methods 2007, 70, 319-328.

16. Peterson, D. S. Matrix-Free Methods for Laser Desorption/Ionization Mass Spectrometry. Mass Spectrom. Rev. 2007, 26, 19-34.

17. Wei, J.; Buriak, J. M.; Siuzdak, G. Desorption-Ionization Mass Spectrometry on Porous Silicon. Nature 1999, 399, 243-246.

18. Seino, T.; Sato, H.; Yamamoto, A.; Nemoto, A.; Torimura, M.; Tao, H. Matrix-Free Laser Desorption/Ionization-Mass Spectrometry Using Self-Assembled Germanium Nanodots. Anal. Chem. 2007, 79, 4827-4832.

19. Huang, Y.-F.; Chang, H.-T. Nile Red-Adsorbed Gold Nanoparticle Matrixes for Determining Aminothiols through Surface-Assisted Laser Desorption/Ionization Mass Spectrometry. Anal. Chem. 2006, 78, 14851493.

20. Teng, C.-H.; Ho, K.-C.; Lin, Y.-S.; Chen, Y.-C. Gold Nanoparticles as Selective and Concentrating Probes for Samples in MALDI MS Analysis. Anal. Chem. 2004, 76, 4337-4342.

21. Su, C.-L.; Tseng, W.-L. Gold Nanoparticles as Assisted Matrix for Determining Neutral Small Carbohydrates through Laser Desorption/ Ionization Time-of-Flight Mass Spectrometry. Anal. Chem. 2007, 79, $1626-1633$.
22. Wu, H.-P.; Su, C.-L.; Chang, H.-C.; Tseng, W.-L. Sample-First Preparation: A Method for Surface-Assisted Laser Desorption/Ionization Timeof-Flight Mass Spectrometry Analysis of Cyclic Oligosaccharides. Anal. Chem. 2007, 79, 6215-6221.

23. Khan, M. A.; Wang, Y.; Heidelberger, S.; Alvelius, G.; Liu, S.; Sjövall, J. Griffiths, W. J. Analysis of Derivatised Steroids by Matrix-Assisted Laser Desorption/Ionisation and Post-Source Decay Mass Spectrometry. Steroids 2006, 71, 42-53.

24. Frens, G. Controlled Nucleation for the Regulation of the Particle Size in Monodispersed Gold Suspensions. Nat. Phys. Sci. 1973, 241, 20-22.

25. Mucic, R. C.; Storhoff, J. J.; Mirkin, C. A.; Letsinger, R. L. DNA-Directed Synthesis of Binary Nanoparticle Network Materials. J. Am. Chem. Soc. 1998, 120, 12674-12675.

26. Garden, R. W.; Moroz, L. L.; Moroz, T. P.; Shippy, S. A.; Sweedler, J. V. Excess Salt Removal with Matrix Rinsing: Direct Peptide Profiling of Neurons from Marine Invertebrates Using Matrix-Assisted Laser Desorption/Ionization Time-of-Flight Mass Spectrometry. I. Mass Spectrom. 1996, 31, 1126-1130.

27. Monroe, E. B.; Koszczuk, B. A.; Losh, J. L.; Jurchen, J. C.; Sweedler, J. V. Measuring Salty Samples without Adducts with MALDI MS. Int. J. Mass Spectrom. 2007, 260, 237-242.

28. Nakamura, K.; Suzuki, Y · Goto-Inoue, N · Yoshida-Noro, C.: Suzuki, A. Structural Characterization of Neutral Glycosphingolipids by ThinLayer Chromatography Coupled to Matrix-Assisted Laser Desorption/ Ionization Quadrupole Ion Trap Time-of-Flight MS/MS. Anal. Chem. 2006, 78, 5736-5743.

29. Chen, W.-Y. Chen, Y.-C. MALDI MS Analysis of Oligonucleotides: Desalting by Functional Magnetite Beads Using Microwave-Assisted Extraction. Anal. Chem. 2007, 79, 8061-8066

30. Nordstrom, A.; Apon, J. V.; Uritboonthai, W.; Go, E. P.; Siuzdak, G. Surfactant-Enhanced Desorption/Ionization on Silicon Mass Spectrometry. Anal. Chem. 2006, 78, 272-278.

31. Tai, S. S.-C.; Xu, B.; Welch, M. J. Development and Evaluation of a Candidate Reference Measurement Procedure for the Determination of Progesterone in Human Serum Using Isotope-Dilution Liquid Chromatography/Tandem Mass Spectrometry. Anal. Chem. 2006, 78, 66286633.

32. Chatman, K.; Hollenbeck, T.; Hagey, L.; Vallee, M.; Purdy, R.; Weiss, F. Siuzdak, G. Nanoelectrospray Mass Spectrometry and Precursor Ion Monitoring for Quantitative Steroid Analysis and Attomole Sensitivity. Anal. Chem. 1999, 71, 2358-2363.

33. (a) Mansson, S.; Colleen, S.; Mardh, P.-A. Urine from Continent Caecal Reservoirs. Studies on Chemical Composition and Bacterial Growth. Eur. Urol. 1989, 16, 18-22; (b) Hugosson, J.; Grenabo, L.; Hedelin, H.; Pettersson, S.; Tarfusser, I. How Variations in the Composition of Urine Influence Urease-Induced Crystallization. Urol. Res. 1990, 18, 413-417. 